\title{
Design of a consensus-based geriatric assessment tailored for older chronic kidney disease patients: results of a pragmatic approach
}

\author{
Carlijn G. N. Voorend ${ }^{1}(1) \cdot$ Hanneke Joosten ${ }^{2} \cdot$ Noeleen C. Berkhout-Byrne $^{1} \cdot$ Adry Diepenbroek $^{3}$.

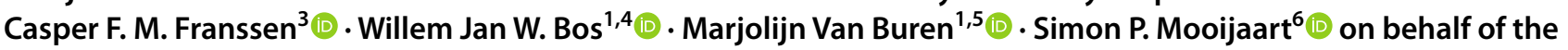 \\ POLDER investigators
}

Received: 18 January 2021 / Accepted: 8 April 2021 / Published online: 19 April 2021

(c) The Author(s) 2021

\section{Key Summary points}

Aim To propose a consensus-based geriatric assessment for optimizing both routine care and research in older patients with advanced chronic kidney disease.

Findings Using a pragmatic approach, we reached consensus on a suitable nephrology-tailored geriatric assessment to routinely identify major geriatric impairments in older patients with advanced chronic kidney disease. This geriatric assessment contains instruments in functional, cognitive, psychological, somatic, patient preferences, nutritional status, and social domains, and can be administered with patient questionnaires and professional-administered instruments by nurse (practitioners) in approximately 20 and 40 minutes, respectively.

Message We propose a consensus test set for standardized nephrology-tailored geriatric assessment, which is currently being implemented in multiple hospitals and studies, to benefit clinical care for older patients with advanced chronic kidney disease and enhance research comparability.

\begin{abstract}
Purpose Unidentified cognitive decline and other geriatric impairments are prevalent in older patients with advanced chronic kidney disease (CKD). Despite guideline recommendation of geriatric evaluation, routine geriatric assessment is not common in these patients. While high burden of vascular disease and existing pre-dialysis care pathways mandate a tailored geriatric assessment, no consensus exists on which instruments are most suitable in this population to identify geriatric impairments. Therefore, the aim of this study was to propose a geriatric assessment, based on multidisciplinary consensus, to routinely identify major geriatric impairments in older people with advanced CKD.
\end{abstract}

Carlijn G. N. Voorend

c.g.n.voorend@lumc.nl

1 Department of Internal Medicine (Nephrology), Leiden

University Medical Center, Leiden, The Netherlands

2 Department of Internal Medicine, Division of General Internal Medicine, Section Geriatric Medicine, Maastricht University Medical Center+, Maastricht, The Netherlands

3 Department of Nephrology, University Medical Centre Groningen, University of Groningen, Groningen, The Netherlands

4 Department of Internal Medicine, St. Antonius hospital, Nieuwegein, The Netherlands

5 Department of Nephrology, Haga Hospital, The Hague, The Netherlands

6 Department of Gerontology and Geriatrics, Leiden University Medical Center, Leiden, The Netherlands 
Methods A pragmatic approach was chosen, which included focus groups, literature review, inventory of current practices, an expert consensus meeting, and pilot testing. In preparation of the consensus meeting, we composed a project team and an expert panel $(n=33)$, drafted selection criteria for the selection of instruments, and assessed potential instruments for the geriatric assessment.

Results Selection criteria related to general geriatric domains, clinical relevance, feasibility, and duration of the assessment. The consensus-assessment contains instruments in functional, cognitive, psychological, somatic, patient preferences, nutritional status, and social domains. Administration of (seven) patient questionnaires and (ten) professional-administered instruments, by nurse (practitioners), takes estimated 20 and $40 \mathrm{~min}$, respectively. Results are discussed in a multidisciplinary meeting including at least nephrology and geriatric expertise, informing nephrology treatment decisions, and follow-up interventions among which comprehensive geriatric assessment.

Conclusion This first multidisciplinary consensus on nephrology-tailored geriatric assessment intent to benefit clinical care and enhance research comparability for older patients with advanced CKD.

Keywords Chronic kidney diseases $\cdot$ Clinical decision-making $\cdot$ Consensus development $\cdot$ Frailty $\cdot$ Aged $\cdot$ Geriatric assessment

\section{Introduction}

Functional and cognitive impairment, frailty, and depression are highly prevalent in patients with advanced chronic kidney disease (CKD stage G4-G5; estimated glomerular filtration rate $[\mathrm{eGFR}] \leq 30 \mathrm{~mL} / \mathrm{min} / 1.73 \mathrm{~m}^{2}$ ) [1-5], but are often unidentified [6]. These impairments are strongly associated with adverse health outcomes such as hospitalization and mortality $[5,7]$, and therefore relevant for risk stratification. Incorporating geriatric evaluation in routine nephrology care could better address older patients' needs [8-11] and is recommended in recently published guidelines $[12,13]$.

Nephrology-specific geriatric assessment could be meaningful, first because the geriatric phenotype is often severely impacted by vascular problems, such as vascular cognitive impairment [14], which necessitates the use of instruments that are sensitive to these impairments. Second, due to the chronic nature of kidney diseases, nephrologists perceive to have a full geriatric picture of their patients' status, but without objective measurements, impairments may still be overlooked [6]. Third and most importantly, broader knowledge of these impairments is important for (future) decisions regarding treatment for these vulnerable patients, and determining goals of ongoing care. Existing pre-decision care pathways mandate a geriatric assessment tailored to the older advanced CKD population. Fourth, a compromise between a full comprehensive geriatric assessment (CGA) and a brief screening (i.e., a modified geriatric assessment) might be a feasible solution to overcome practical barriers of implementation [8]. Comprehensive geriatric assessment (CGA), the cornerstone of geriatric medicine, has to conducted by a geriatrician and includes three elements; (i) thorough assessment of an older patient's physical, functional, cognitive, and social capabilities, uncovering otherwise unnoticed impairments and detection of frailty, (ii) development of an integrated treatment plan, and (iii) evaluation of the progression of impairments and accordingly adjustment of the plan. CGA has shown to enable therapy adjustments and estimation of outcomes such as patient's likelihood of living at home, limiting deterioration, and avoiding death $[15,16]$. Yet, this systematic interdisciplinary process is time-consuming and therefore impracticable to use routinely in older CKD patients. Contrarily, geriatric screening with brief questionnaires is conduced to assess frailty and potential need for geriatric referral. However, this approach has lacked discriminating abilities to adequately recognize geriatric impairments or frailty in CKD patients [17]. Instead, we direct towards a geriatric assessment that aims to assess patients on all geriatric domains using validated questionnaires without necessary involvement of a geriatrician. Such a modified nephrology-specific geriatric assessment could be conducted by a trained nephrology nurse and be discussed in a multidisciplinary meeting, informing nephrology treatment decisions and follow-up interventions among which geriatric assessment identifies those patients who may benefit from CGA. In this model, the geriatrician adds valuable expertise on clinical judgement of frailty and appropriate interventions for older patients in addition to the nephrologists' knowledge of the patient and the disease [18]. Clinicians have recognized that a standardized set of instruments could benefit these clinical purposes [5, 19].

In the absence of consensus on a uniform geriatric assessment for patients with advanced CKD, our aim was to propose a nephrology-tailored geriatric assessment, based on multidisciplinary consensus, useful in routine clinical care for older patients with advanced CKD.

\section{Methods}

The current study aimed to reach agreement on a nephrology-tailored geriatric assessment (NGA) suitable to routinely identify major geriatric impairments in the target population, which was defined as older patients $(\geq 65$ years 
of age) with stage G4-G5 CKD. Ultimately, the test set should be ready to be implemented and evaluated in routine practice. Therefore, a pragmatic approach was chosen, which included focus group meetings to identify criteria for the assessment, literature review to identify potential instruments, questionnaires to inventory currently used instruments, an expert consensus meeting to ensure that the selection of tests was based on input from patients, clinical experience in nephrology and geriatrics, and pilot testing to ensure practicability. In preparation of the consensus meeting, we composed a project team and an expert panel, drafted selection criteria for the selection of instruments, and assessed potential instruments for the test set. After the consensus meeting, the set was pilot tested.

\section{Composition of the project team and expert panel}

A multidisciplinary project team was formed, consisting of nephrologists (MB, WB, and $\mathrm{CF}$ ), a geriatrician (SM), a nephrologist-geriatrician (HJ), nurse practitioners in nephrology $(\mathrm{AD}$ and $\mathrm{NB})$, and a project leader $(\mathrm{CV})$, to guide and prepare the consensus process. A multidisciplinary expert panel of 33 healthcare professionals was selected by an open purposive invitation for a meeting to find consensus on a preliminary test set. We invited medical doctors, nurses, and supportive disciplines experienced in the care for older kidney patients and/or with scientific experience in geriatric nephrology (Table 1).

\section{Identifying potential selection criteria}

A list of basic principles for geriatric assessment in nephrology was drafted by the project group, based on clinical and scientific expertise of the project team and general principles of geriatric assessment. The latter includes a holistic view of the patients' unique needs and preferences, and assessment of health status in four domains (i.e., physical, cognitive, functional, and social), aiming to maximize self-reliance and quality of life.

In-depth input from older patients with advanced CKD, caregivers, and health care professionals experienced with conducting geriatric assessment in nephrology care was gathered in six focus group meetings. Purposively sampled CKD patients were included if aged $\geq 65$ years, had an eGFR $<20 \mathrm{ml} / \mathrm{min} / 1.73 \mathrm{~m}^{2}$ ), and had experience with geriatric assessment practices. Both patients with positive and negative experiences with NGA and with different (future) choices of treatment modality were invited, as were their caregivers. Detailed methods and overall results of these focus groups are published elsewhere [18]. Findings were included in the list of basic principles for geriatric assessment in nephrology which was presented and discussed in the expert meeting described below.
Table 1 List of participants of the expert meeting $31^{\text {st }}$ of January, and input via round of comments

\begin{tabular}{ll}
\hline Discipline & $\begin{array}{l}\text { Number of } \\
\text { participants } \\
(n=33)\end{array}$ \\
\hline Nephrologist (i.t) & 12 \\
Geriatrician (i.t) & 5 \\
Medical doctor (otherwise) & 1 \\
Nephrologist/geriatrician & 2 \\
Nurse practitioner (nephrology) & 6 \\
Nurse (nephrology) & 3 \\
Social worker & 1 \\
Physician assistant (i.t) & 1 \\
Other: medical information officer, project leader & 2 \\
\hline
\end{tabular}

i.t. in training

\section{Selection of potential instruments}

Scientific use of geriatric tests was enumerated in published nephrology literature. We critically appraised previous systematic reviews [5, 7] and experience from (national ongoing) research cohorts in older patients with CKD G4-G5(D) [3, 6, 8, 11, 20, 21]. Tests with evidencebased associations with outcomes in older (CKD) patients were prioritized. In preparation of the consensus phase, two potential test sets were created to illustrate how the selection criteria and preconditions could work out in a practical test set.

Potential instruments for NGA were selected on the basis of current clinical and research practices. Clinical use was inventoried in 14 large Dutch academic and peripheral nephrology centers (comprising $25 \%$ of all Dutch nephrology centers). The centers were purposively selected based on their interest in implementation of geriatric assessment practices in nephrology. A questionnaire was sent to a nephrologist of each of the 14 centers by e-mail to ask for current and preferred geriatric screening instruments or assessment practices.

\section{Consensus meeting}

The expert panel was invited to a meeting (January $31^{\text {st }}$ 2018) to discuss and reach consensus on a preliminary test set. Main aims of the meeting was to agree on (1) the proposed selection criteria, (2) the geriatric and clinical domains to be appraised, and (3) the selection of potential instruments. After the meeting, the preliminary test set was sent for a final round of comments to all attendees of the meeting, to experts who could not attend the meeting, and to a clinical neuropsychologist. Their feedback was discussed within the project group. 


\section{Final test set}

The final geriatric assessment was subsequently pilot tested by two experienced nurse practitioners from the project team (NB, AD), in two patients from different hospitals (patients aged 74 and 78 years, estimated glomerular filtration rate 18 and $26 \mathrm{ml} / \mathrm{min} / 1.73 \mathrm{~m}^{2}$, respectively), to estimate administration time and patient and provider acceptability.

\section{Ethics information}

This study is a narrative of a pragmatic consensus approach to improve routine clinical care, for which ethical approval is not applicable. Except for the qualitative part of the research using focus group discussions, which was approved by the Medical Research Ethics Committee United (MEC-U, Nieuwegein, The Netherlands, reference W17.127).

\section{Results}

\section{Selection criteria}

Table S1 presents the description of the generic purposes of the geriatric screening, criteria for selection of tests and questionnaires, criteria for feasibility, and duration of the assessment. Results of the focus group meetings [18] yielded five additional essential points: i.e., awareness of illiteracy, burden for patients, learning effect in case of repeated measurements over time, feasibility to conduct the NGA next to other local preferred instruments, and unpracticality of performing walking tests in the outpatient-clinic.

\section{Selection of instruments}

The inventory of current geriatric screening instruments or assessment practices had a response rate of $100 \%$. Supplementary Table S2 shows that 8 out of the 14 hospitals incorporated some form of geriatric screening or assessment in routine care for CKD G4-G5 patients, of which three for study purposes only. Among the hospitals, different screenings tests were used. Table $\mathrm{S} 3$ provides an overview of geriatric assessments as used in these hospitals and described in nephrology literature $[3,6,8,11,20,21]$.

\section{Reaching consensus on the domains and measures}

In the expert panel meeting, first, the panel agreed on the selection criteria as proposed (i.e., basic principles for geriatric assessment in nephrology; Table S1), and underlined that feasibility was of utmost importance for use in routine care. Possible barriers were discussed: e.g., burden for patients, desirable answers, over testing, illiteracy and multi-ethnical patient population, duplication of locally used tests, unavailability of geriatricians, availability of time for conducting the assessment, and conflicting interests between pragmatic routine care and science. Second, the panel suggested three major changes after discussing two potential test sets. Primary, the panel agreed on including items of health-related quality of life (HRQoL) and patient preferences that correspond with the recently implemented Dutch patient-reported outcome measures (PROMs) for nephrology [22]. Secondary, the Montreal Cognitive Assessment (MoCA) was preferred over Mini-Mental State Examination (MMSE) for identifying mild cognitive impairment within the CKD population, especially because the latter is less in-depth and less discriminating [23, 24]. Tertiary, difficulties were recognized in standardized measurement of social domain. At the end of the meeting, consensus was reached on a preliminary test set including instruments for functional status, cognitive functioning, mood/psychological functioning, patient preferences, and frailty.

After the subsequent round of comments, the test set was changed on three aspects: instruments for assessing nutritional status and fall risk were added, and the Visual Association Test (VAT) was substituted by the Letter Digit Substitution Test (LDST) for the need of a more specific executive function test. The assessment comprises of patient questionnaires (seven instruments, including one caregiver questionnaire) and a test set administered by a professional (ten instruments).

\section{Items of the final consensus-based test set}

Instruments are described below, and the main characteristics and cut-off points are summarized in Table 2. Supplementary Table $\mathrm{S} 4$ shows the predictive and diagnostic performance of tests in chronic kidney disease patients.

\section{Functional and performance status}

Two instruments were selected to assess functional dependency. Katz Activities of Daily Living score (Katz-ADL-6) [25] was included to measure self-reported task for self-care on six functions of daily living activities; such as dressing and bathing. Whereas the Lawton scale for instrumental Activities of Daily Living (Lawton-iADL or $\mathrm{IADL}_{8}$ ) [26] measures more complex skills required for independent living in the community, such as handling finances and medication. Third measure of functional status is handgrip strength, which was considered important as it is associated with risk of commencing dialysis, and higher physical domain QOL scores [27]. Measure of gait speed was also considered as a sensitive and often used measure, but eventually not preferred above handgrip strength for practical reasons (i.e., gait speed assessment requires four to six meters of free space). 


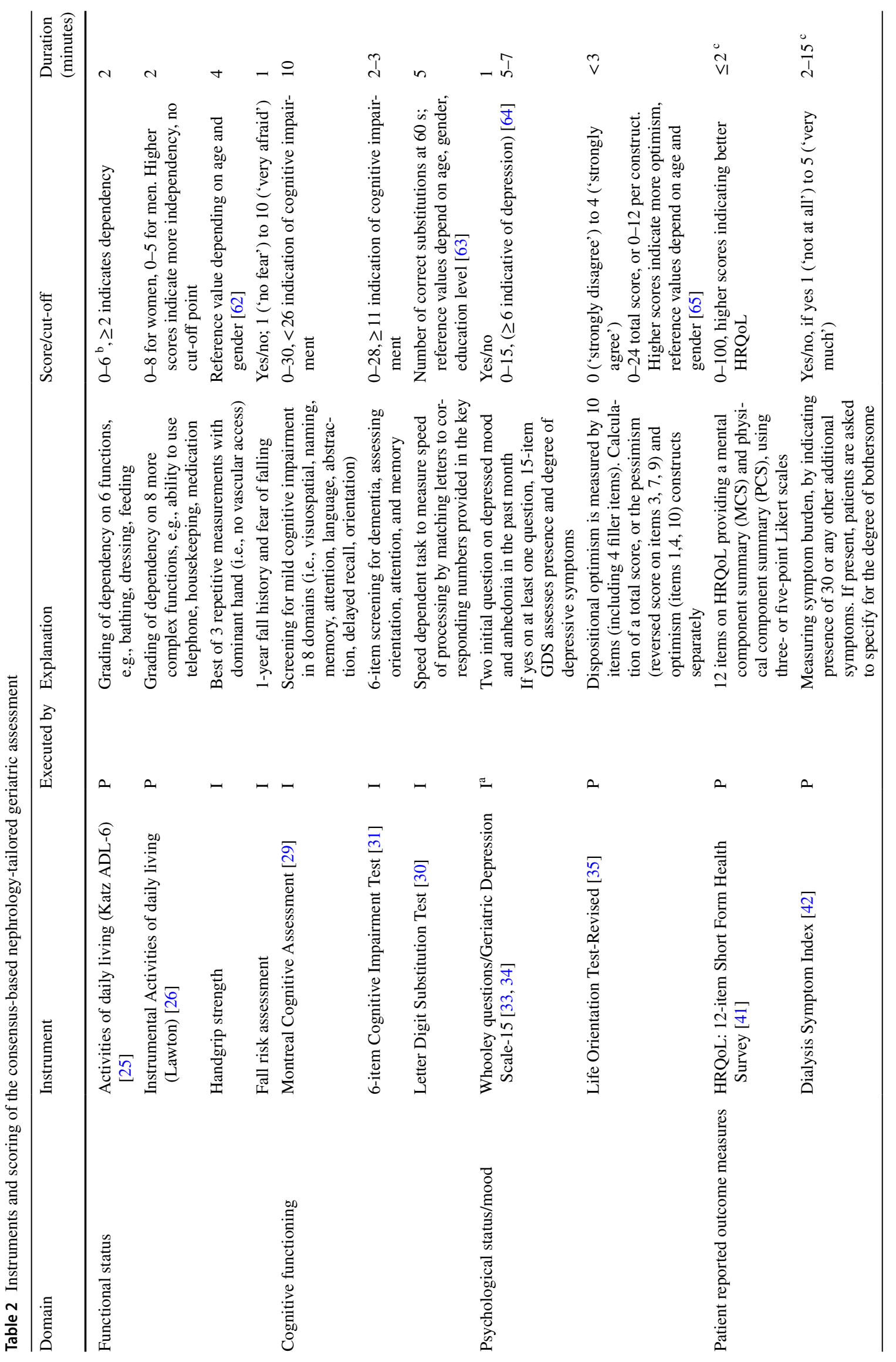




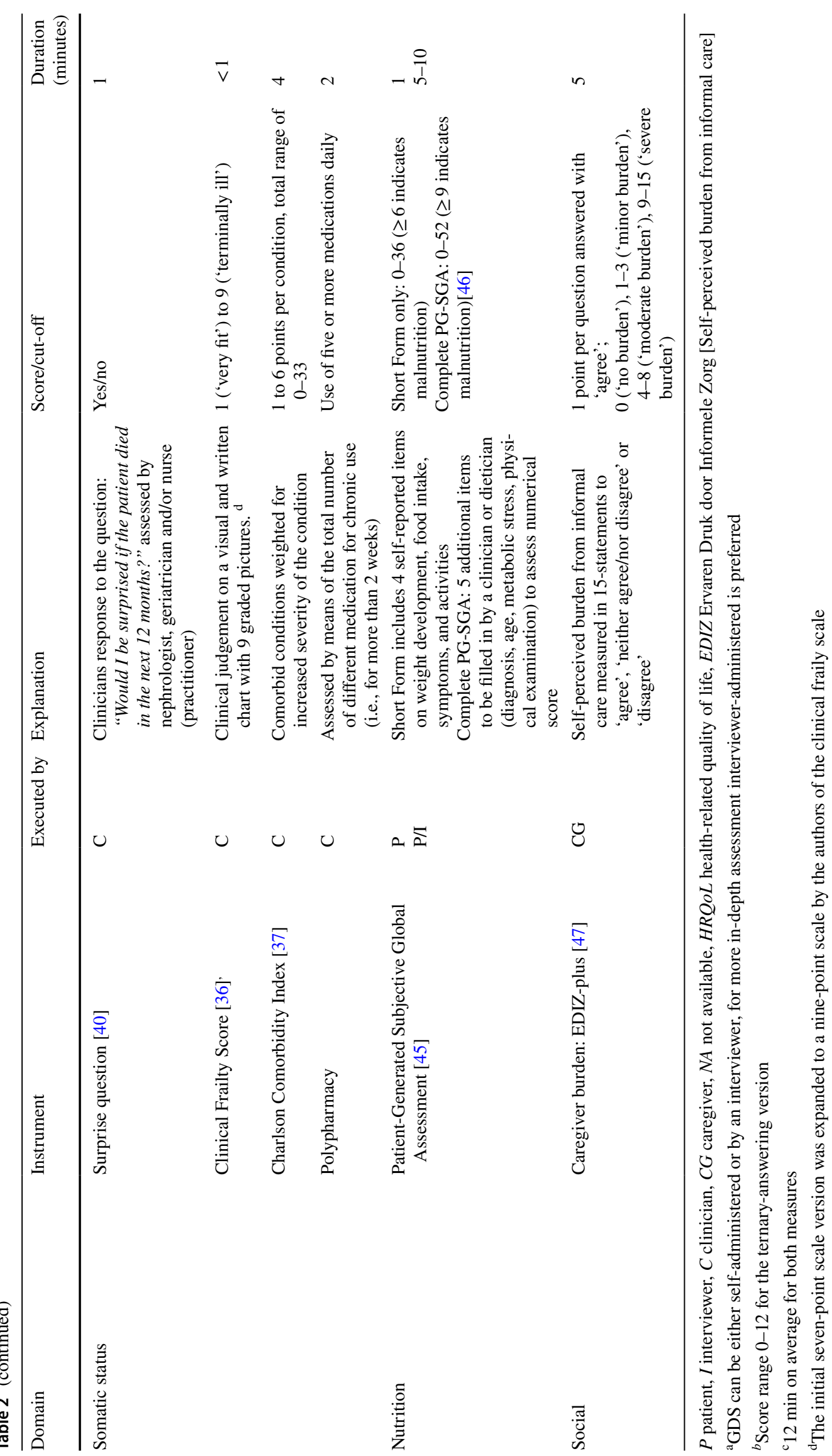


Fourth, it was considered important to assess a person's fall risk, as among older dialysis, patients falls are frequent and negatively impact HRQoL [28]. Two short questions were included on 1-year fall history and fear of falling. In summary, physical functioning is assessed by Katz-ADL-6, Lawton iADL, handgrip strength, and falls questionnaire in this final NGA.

\section{Cognitive functioning}

Three cognitive tests were included (i.e., MoCA, LDST, and six-item cognitive impairment test [6-CIT]), to ensure all unidentified cognitive deficits were captured. Besides, multiple tests allow future selection of the best fitting instrument to our population. The MoCA [29] is developed to measure cognitive decline in multiple cognitive domains, such as executive function, orientation, recall, and visuospatial ability. The LDST [30] is used in CKD G4-G5 patients [14] to measure the speed of processing general information. The 6-CIT [31] is a screening instrument for dementia, assessing only six items on orientation, attention, and memory. The 6-CIT is a feasible, acceptable, short, and simple instrument [32], which was a key reason for incorporating the test in the NGA set, and allowing further research to potentially replace MoCA and LDST by a shorter instrument.

\section{Psychological functioning/mood}

Depression is assessed in two steps. First, a validated twoitem case-finding instrument is used, asking about depressed mood and anhedonia in the past month ('Whooley-questions') [33]. If at least one question is answered positive, the binary 15-item Geriatric Depression Scale (GDS-15) [34] will be assessed. GDS-15 is specifically designed for older persons by putting less weight into somatic symptoms as these may be part of comorbidity. The 10-item Life Orientation Test-Revised (LOT-R) [35] is used to assess dispositional optimism and pessimism. In summary, psychological functioning is assessed by the LOT-R and 'Whooley-questions' and GDS-15 in this final NGA.

\section{Somatic status/clinical judgement}

Consensus was reached about the inclusion of three different predictive measures of mortality: frailty, comorbidity, and the surprise question. Frailty is measured using the Clinical Frailty Scale (CFS) [36], i.e., clinical judgement score on a visual and written chart with nine graded pictures, varying from very fit tot terminally ill. Second, comorbidity is assessed with the Charlson Comorbidity Index [37], a score calculated by the patient's comorbid conditions weighted for increased severity of the condition. It is the most common used validated prognostic index to predict mortality for CKD patients starting dialysis [38]. Finally, the surprise question (i.e., 'Would I be surprised if the patient died in the next 12 months?') was included, since it performs as a predicter for death in CKD populations and because it is a simple and feasible instrument $[39,40]$.

\section{Patient preferences and HRQoL}

The 12-item Short Form (SF-12) and the Dialysis Symptom Index (DSI) were recently introduced as PROMs in Dutch Nephrological Care by the Dutch Kidney Patients' Association, Dutch Federation of Nephrology, and Nefrovisie Foundation. SF-12 is a measure of eight domains of HRQoL, comprising of a mental- and a physical component summary score [41]. The DSI is a measure of symptom burden [42]. Patients are asked to indicate and rate the presence of 30 possible symptoms during the past week. Discussing symptoms could provide insights and guidance in symptom burden and management [43, 44].

\section{Other domains: nutrition, caregiver burden, and polypharmacy}

Nutritional status is assessed by the Patient-Generated Subjective Global Assessment (PG-SGA) [45]. The PG-SGA contains a patient-questionnaire on intake, symptoms and physical activities (i.e., PG-SGA Short Form), and a professional part on subjective clinical judgement. The instrument can be used as a triage tool for nutritional interventions and to identify malnourished patients [46].

Caregiver burden is measured (optional) with a 'selfperceived burden of informal care' 15 -item questionnaire (EDIZ-plus) [47], which can indicate overburdening of caregivers.

Polypharmacy, defined by use of five or more medications daily, is assessed by means of the total number of different medications for chronic use (i.e., for more than 2 weeks).

\section{Pilot testing}

The geriatric assessment was pilot tested and took 20-30 min for the patient questionnaire and 30-45 min for the professional-administered set. Patient and professional acceptability was ensured as both nurse practitioners and patients did not have any remarks.

\section{Discussion}

We propose a consensus-based nephrology-tailored geriatric assessment (NGA) suitable to routinely identify major geriatric impairments in older patients with advanced chronic kidney disease. The NGA contains instruments in functional, 
cognitive, psychological, somatic, patient preferences, nutritional status, and social domains. Selection of instruments resulted from focus group meetings with patients and professionals, literature evidence, inventory of current geriatric screening practices, consensus between clinicians from nephrology and geriatrics, and pilot testing. This first consensus-based geriatric assessment is intended for use in nephrology clinical practice, and can be seen as a first pragmatic step towards implementation of standardized geriatric practices in nephrology.

Other fields, such as oncology, have previously reported studies on the pivotable role of geriatric assessment for treatment decisions and plans [20, 48, 49], the development of new approaches for geriatric assessment [50-52], and consensus trajectories for these new approaches [53-55]. However, such initiatives are relatively new to the field of nephrology, where only a few NGA practices have been published. One example is the Renal Elderly Care Integration Project $[8,10]$ which presented a 'modified geriatric assessment' using similar domains compared to our proposed geriatric assessment. The main difference to our set is the choice of patient experiences (Renal Treatment Satisfaction Score and Distress thermometer) compared to our inclusion of PROMs measures [43], and the addition of instruments on nutritional status and caregiver burden. Compared to other geriatric assessment initiatives in nephrology, our set is more holistic than the presented set for the CGA-4-CKD and Renal Silver Program [20], and the Multi Prognostic Index [56], and more compact, benefitting use in routine practice, than sets designed for research $[3,6,21]$. Another recent initiative presented positive results on quality improvement by combined frailty screening and geriatric assessment practices [57].

For both the somatic and social domain, limited instruments were selected, under the assumption that regular anamnesis already addresses most somatic deficits. Our final consensus NGA may be considered a minimum data set, but is not all-inclusive. Additional domains and instruments may be of local interest and beneficial for the patient to assess; e.g., spiritual beliefs, life goals, physical fitness, cumulative illness rating scale, self-efficacy, health-literacy assessment, and patients' outcome prioritizations. The proposed set consists of instruments that have been established in clinical or scientific use in aged populations, although some instruments (e.g., 6-CIT, LDST, LOT-R, CFS) should be further tested for use in CKD G4-G5 patients, as illustrated in Table S4. The geriatric assessment is aimed complementary to routine data collection as part of nephrology care (including, e.g., CKD classification, metabolic and cardiovascular parameters, cohabitation status, and history of smoking/alcohol use).

Implementation of geriatric assessment may differ locally, since health settings and structures diverge. Contrary to a time and labor-intensive CGA, the proposed NGA in this article is feasible within $1 \mathrm{~h}$ and could be assessed without involvement of a geriatrician. Rather, results are discussed in a multidisciplinary meeting, informing nephrology treatment decisions and follow-up interventions among which CGA and consultation of a geriatrician. The NGA could be conducted by a geriatric-trained nephrology nurse (practitioner) or by a partnership between geriatric medicine and nephrology (i.e., geriatrician co-management after screening for eligibility by geriatrician or triage nurse) as described elsewhere [18, 20]. However, appropriate geriatric training for clinicians to assess and manage geriatric conditions is advocated $[3,6,8,10,20,21]$. Also, at least minimal geriatric involvement is recommended $[55,58]$. Logistical difficulties of implementing geriatric assessment in new settings, like involving geriatricians and other team members being added to existing services, should not be under-estimated [50]. Factors, such as stretching budgets [50], shortage of geriatricians [55], and lack of knowledge on geriatric tools $[8,59]$, may hamper practical implementation.

Controversy still exists regarding the selection of patients for whom NGA is beneficial [50]. Due to considerable heterogeneity in the aging process, actual age may not always be useful. In oncology, patients' age cut-off for assessment is often $\geq 70$ years[53], but also those who are younger with age-related issues or concerns were recommended for assessment [55]. In nephrology, assessment has been reported from age of $65[3,6,11,21]$ or 70 years $[8,20]$, or younger if a patient is considered frail. Furthermore, timing of assessment is subject to further investigation. To optimally benefit the decision-making process, we advocate geriatric assessment in (late) CKD stage-G4 [20, 21], rather than at initiation or during dialysis $[6,8]$.

Strengths of our presented NGA test set is that it is a first consensus-proposal, based on current routine practices, with input from patients and a multidisciplinary expert panel. There are several limitations. First, this appraisal was neither based on a formal Delphi-method or nominal group technique, nor a systematic review of literature. Rather, our pragmatic consensus approach was seen as a first step to implementation of a standardized geriatric assessment in nephrology care. After evaluation of the NGA, subsequent Delphi-method may be useful in further implementation and development, as was done in oncology [54]. Second, bias is an inherent risk in consensus approaches, e.g., in selection of our expert panel. Although we aimed to represent all disciplines involved in CKD G4-G5 care, the panel was a selected group of Dutch professionals with special interest in the field of nephrogeriatrics, and may not reflect the general nephrology opinion. A third limitation is that the test set is less suitable in illiterate patients. Furthermore, although CGA has demonstrated benefits in other medical fields [15, 16], studies on its effectiveness are lacking. Though, use of 
a geriatric assessment was suggested to identify often undiagnosed problems [6], raise awareness for these problems among health care professionals $[3,18,20]$, and enables treatment adjustment or tailored supportive interventions [48]. Besides, the information derived from standardized geriatric assessment can potentially be used to stratify patients into risk categories to better predict their outcomes on kidney replacement therapy or conservative care [5].

Future research is needed to evaluate the effectiveness and feasibility of implementation of the set. Also, value of NGA for decision-making, which is an extremely complex process, should be further explored. Therefore, insights in determinants of adverse outcomes and exploration of the prognostic capacity on outcomes are needed. Furthermore, (cost)effectiveness of geriatric assessment on key outcomes such as quality of life, hospitalization, treatment, and survival needs to be investigated in the older nephrology population. Along with the identification of standardized (preventive) clinical interventions for the management of geriatric impairments. As a first step, the NGA is currently implemented in 11 Dutch hospitals. In a pilot study [60], we will explore feasibility of implementation of the NGA in routine nephrology care and evaluate the included instruments (outcomes are expected in 2021). Experience and data from succeeding prospective cohort studies [61] could ultimately lead to prediction models to guide tailored treatment decisions or preventive interventions.

In conclusion, we propose a consensus-based nephrology-tailored geriatric test set to assess frailty, cognitive and functional status for older patients approaching kidney failure (CKD G4-G5), in accordance with (inter)national guidelines and suitable to routinely identify major geriatric impairments. Future research should investigate feasibility of implementation of this NGA and its value for decisionmaking trajectories for kidney replacement therapy, providing insights in determinants of adverse outcomes, and for improvement outcomes for older kidney failure patients.

Supplementary Information The online version contains supplementary material available at https://doi.org/10.1007/s41999-021-00498-0.

Acknowledgements We are grateful to all healthcare professionals who participated in the expert panel, and the patients and healthcare professionals who participated in pilot testing.

Group information The Pathway for older patients reaching end stage renal disease (POLDER) study group is a collaboration in the Netherlands that is established to study and implement a nephrology-tailored geriatric assessment in routine care. The POLDER investigators are (in alphabetical order): Arjan van Alphen, Maasstad Hospital Rotterdam; Noeleen Berkhout-Byrne, Leiden University Medical Centre; Fenna van Breda, Amsterdam University Medical Centre; Marjolijn van Buren, Haga Ziekenhuis The Hague; Henk Boom, Reiner de Graaf Hospital Delft; Willem Jan Bos, St. Antonius Hospital Nieuwegein; Adry Diepenbroek, University Medical Centre Groningen; Marielle Emmelot-Vonk, University Medical Centre Utrecht; Casper Franssen,
University Medical Centre Groningen; Carlo AJM Gaillard, University Medical Centre Utrecht; Nel Groeneweg, Reinier de Graaf Hospital Delft; Bettie Hoekstra, Maasstad Hospital Rotterdam; Nienke Hommes, Haaglanden Medical Centre The Hague; Francoise Hoornaar, St. Antonius Hospital Nieuwegein; Hanneke Joosten, Maastricht University Medical Centre; Joep Lagró, Haga Hospital; Elisabeth Litjens, Maastricht University Medical Centre; Femke Molenaar, University Medical Centre Utrecht; Simon P Mooijaart, Leiden University Medical Centre; Aegida Neradova, Dianet Amsterdam, Amsterdam University Medical Centre; Mike Peters, Amsterdam University Medical Centre; Wilma Veldman, University Medical Centre Groningen; Carlijn Voorend, Leiden University Medical Centre; Lidwien Westerbos, Amsterdam University Medical Centre; Carlijne Westerman- van der Wijden, Haaglanden Medical Centre The Hague; Judith Wierdsma, University Medical Centre Utrecht.

POLDER advisory board members are: M. Hemmelder (Chair), Nefrovisie Foundation, and Department of Internal Medicine, Maastricht University Medical Centre; J.J Homan van der Heide, Amsterdam Medical University Centre; K. Prantl, Dutch Kidney Patients' Association Association of renal patients (NVN); A. J. Rabelink, Leiden University Medical Centre; S. de Rooij, University Medical Centre Groningen, Medisch Spectrum Twente hospital; C. Stehouwer, CARIM School for Cardiovascular Diseases, Maastricht University (UM), The Netherlands, and Department of Internal Medicine, Maastricht University Medical Center + (MUMC), The Netherlands.

Authors' contributions All authors contributed to the study conception and design. Material preparation, data collection, and analysis were performed by Carlijn G. N. Voorend, Hanneke Joosten, and Simon P. Mooijaart. The first draft of the manuscript was written by Carlijn G. $\mathrm{N}$. Voorend and all authors commented on previous versions of the manuscript. All authors read and approved the final manuscript.

Funding The study was funded by Dutch Kidney Foundation (A1D3P04), as part of a project to design and implement a nephrologytailored geriatric care pathway: Pathway for OLDer patients reaching End-stage Renal disease (POLDER). The Dutch Kidney Foundation did not play any role in design, collection, analysis, and interpretation of data; writing the perspective; or the decision to submit for publication. The expert panel did not receive any fees or funding for travel. CV is partly funded by the Nephrosearch Foundation.

Availability of data and materials Not applicable.

\section{Declarations}

Conflicts of interests WB reports grants from Zilveren Kruis Insurance, outside the submitted work. The remaining authors have nothing to disclose.

Consent to participate Not applicable for consensus trajectory. Participants of the focus group discussions provided informed consent before participating.

Consent for publication Not applicable.

Ethics approval This study is a narrative of a pragmatic consensus approach, for which ethical approval is not applicable. The part concerning qualitative research (focus group discussions with patients and professionals) was approved by the Medical Research Ethics Committee United (MEC-U, Nieuwegein, The Netherlands, reference W17.127). Future implementation and data collection of the nephrology-tailored geriatric assessment in a feasibility study were approved 
by the Medical Ethical Committee Zuidwest Holland (The Hague, The Netherlands, reference N165322.098.18).

Open Access This article is licensed under a Creative Commons Attribution 4.0 International License, which permits use, sharing, adaptation, distribution and reproduction in any medium or format, as long as you give appropriate credit to the original author(s) and the source, provide a link to the Creative Commons licence, and indicate if changes were made. The images or other third party material in this article are included in the article's Creative Commons licence, unless indicated otherwise in a credit line to the material. If material is not included in the article's Creative Commons licence and your intended use is not permitted by statutory regulation or exceeds the permitted use, you will need to obtain permission directly from the copyright holder. To view a copy of this licence, visit http://creativecommons.org/licenses/by/4.0/.

\section{References}

1. Racic M, Petkovic N, Bogicevic K, Maric I, Matovic J, Pejovic $\mathrm{V}$ et al (2015) Comprehensive geriatric assessment: comparison of elderly hemodialysis patients and primary care patients. Ren Fail 37:1126-1131

2. Palmer S, Vecchio M, Craig JC, Tonelli M, Johnson DW, Nicolucci A et al (2013) Prevalence of depression in chronic kidney disease: systematic review and meta-analysis of observational studies. Kidney Int 84:179-191

3. Parlevliet JL, Buurman BM, Pannekeet MM, Boeschoten EM, ten Brinke L, Hamaker ME et al (2012) Systematic comprehensive geriatric assessment in elderly patients on chronic dialysis: a cross-sectional comparative and feasibility study. BMC Nephrol 13:30

4. Canaud B, Tong L, Tentori F, Akiba T, Karaboyas A, Gillespie $B$ et al (2011) Clinical practices and outcomes in elderly hemodialysis patients: results from the Dialysis Outcomes and Practice Patterns Study (DOPPS). Clin J Am Soc Nephrol 6:1651-1662

5. Kallenberg MH, Kleinveld HA, Dekker FW, van Munster BC, Rabelink TJ, van Buren M et al (2016) Functional and cognitive impairment, frailty, and adverse health outcomes in older patients reaching ESRD-a systematic review. Clin J Am Soc Nephrol 11:1624-1639

6. Goto NA, van Loon IN, Morpey MI, Verhaar MC, Willems HC, Emmelot-Vonk MH et al (2019) Geriatric assessment in elderly patients with end-stage kidney disease. Nephron 141:41-48

7. van Loon IN, Wouters TR, Boereboom FT, Bots ML, Verhaar MC, Hamaker ME (2016) The relevance of geriatric impairments in patients starting dialysis: a systematic review. Clin J Am Soc Nephrol 11:1245-1259

8. Brown EA, Farrington K (2019) Geriatric assessment in advanced kidney disease. Clin J Am Soc Nephrol 14:1091-1093

9. Brown EA, Bargman JM, Li PK (2015) Managing older patients on peritoneal dialysis. Perit Dial Int 35:609-611

10. Abdulla A, Wright PN, Ross LE, Gallagher H, Iyasere O, Ma N et al (2017) Proceedings from the symposium on kidney disease in older people: royal society of medicine, London, January 19, 2017. Gerontol Geriatr Med 3:2333721417736858

11. Soysal P, Isik AT, Buyukaydin B, Kazancioglu R (2014) A comparison of end-stage renal disease and Alzheimer's disease in the elderly through a comprehensive geriatric assessment. Int Urol Nephrol 46:1627-1632

12. Farrington K, Covic A, Aucella F, Clyne N, de Vos L, Findlay A, et al. Clinical Practice Guideline on management of older patients with chronic kidney disease stage $3 \mathrm{~b}$ or higher (eGFR $<45 \mathrm{~mL} / \mathrm{min} / 173 \mathrm{~m} 2$ ). Nephrol Dial Transplant. 2016; 31: 1-66

13. Nederlandse Internisten Vereniging / Federatie van Medisch Specialisten [Dutch Society of Internal Medicine / Dutch Association of Medical Specialists]. Richtlijn Nierfunctievervangende behandeling [Guideline on Renal Replacement Therapy]. Kennisinstituut van de Federatie van Medisch Specialisten. 2016. https://richtlijnendatabase.nl/richtlijn/nierfuncti evervangende_behandeling/nierfunctievervangende_behandelin g_-_startpagina.html. Accessed 13 Aug 2019.

14. van Deudekom FJ, Kallenberg MH, Berkhout-Byrne NC, Blauw GJ, Boom H, de Bresser J et al (2020) Patterns and characteristics of cognitive functioning in older patients approaching end stage kidney disease, the COPE-study. BMC Nephrol 21:126

15. Ellis G, Gardner M, Tsiachristas A, Langhorne P, Burke O, Harwood RH et al (2017) Comprehensive geriatric assessment for older adults admitted to hospital. Cochrane Database Syst Rev. 9:CD006211

16. Stuck AE, Siu AL, Wieland GD, Adams J, Rubenstein LZ (1993) Comprehensive geriatric assessment: a meta-analysis of controlled trials. Lancet 342:1032-1036

17. van Loon IN, Goto NA, Boereboom FTJ, Bots ML, Verhaar MC, Hamaker ME (2017) Frailty screening tools for elderly patients incident to dialysis. Clin J Am Soc Nephrol 12:1480-1488

18. Voorend CGN, Berkhout-Byrne NC, Meuleman Y, Mooijaart SP, Bos WJW, van Buren M (2021) Perspectives and experiences of patients and healthcare professionals with geriatric assessment in chronic kidney disease: a qualitative study. BMC Nephrol 22:9

19. Oud FMM, de Rooij S, Arends AJ, Emmelot-Vonk MH, Melis RJF, Mooijaart SP et al (2019) Assessment instruments in frail older patients; a call for more standardisation. Ned Tijdschr Geneeskd 163:D3267

20. Hall RK, Haines C, Gorbatkin SM, Schlanger L, Shaban H, Schell JO et al (2016) Incorporating geriatric assessment into a nephrology clinic: preliminary data from two models of care. J Am Geriatr Soc 64:2154-2158

21. Berkhout-Byrne N, Kallenberg MH, Gaasbeek A, Rabelink TJ, Hammer S, van Buchem MA et al (2017) The Cognitive decline in Older Patients with End stage renal disease (COPE) study rationale and design. Curr Med Res Opin 33:2057-2064

22. van der Willik EM, Hemmelder MH, Bart HAJ, van Ittersum FJ, van den Akker JM, Bos WJW et al (2020) Routinely measuring symptom burden and health-related quality of life in dialysis patients: first results from the Dutch registry of patient-reported outcome measures. Clin Kidney J. https://doi.org/10.1093/ckj/ sfz192

23. Ciesielska N, Sokolowski R, Mazur E, Podhorecka M, PolakSzabela A, Kedziora-Kornatowska K (2016) Is the Montreal Cognitive Assessment (MoCA) test better suited than the Mini-Mental State Examination (MMSE) in mild cognitive impairment (MCI) detection among people aged over 60? Meta-analysis Psychiatr Pol 50:1039-1052

24. Tiffin-Richards FE, Costa AS, Holschbach B, Frank RD, Vassiliadou A, Kruger T et al (2014) The Montreal Cognitive Assessment (MoCA) - a sensitive screening instrument for detecting cognitive impairment in chronic hemodialysis patients. PLoS ONE 9:e106700

25. Katz S, Ford AB, Moskowitz RW, Jackson BA, Jaffe MW (1963) Studies of illness in the aged The index of ADL: a standardized measure of biological and psychosocial function. JAMA 185:914-919

26. Lawton MP, Brody EM (1969) Assessment of older people: selfmaintaining and instrumental activities of daily living. Gerontologist 9:179-186

27. Tsai YC, Chen HM, Hsiao SM, Chen CS, Lin MY, Chiu YW et al (2017) Association of physical activity with cardiovascular and 
renal outcomes and quality of life in chronic kidney disease. PLoS ONE 12:e0183642

28. van Loon IN, Goto NA, Boereboom FTJ, Verhaar MC, Bots ML, Hamaker ME (2019) Quality of life after the initiation of dialysis or maximal conservative management in elderly patients: a longitudinal analysis of the Geriatric assessment in OLder patients starting Dialysis (GOLD) study. BMC Nephrol 20:108

29. Nasreddine ZS, Phillips NA, Bedirian V, Charbonneau S, Whitehead V, Collin I et al (2005) The Montreal Cognitive Assessment, MoCA: a brief screening tool for mild cognitive impairment. J Am Geriatr Soc 53:695-699

30. Jolles J, Houx P, van Boxtel M, Ponds R. The Maastricht Aging Study: Determinants of Cognitive Aging. Maastricht: Neuropsych Publishers; 1995. https://breinweb.nl/maas/assets/maas_pb_intro. pdf. Accessed at 27 Jan 2020.

31. Katzman R, Brown T, Fuld P, Peck A, Schechter R, Schimmel H (1983) Validation of a short orientation-memory-concentration test of cognitive impairment. Am J Psychiatry 140:734-739

32. O'Sullivan D, Brady N, Manning E, O'Shea E, O'Grady S et al (2018) Validation of the 6-Item Cognitive Impairment Test and the 4AT test for combined delirium and dementia screening in older Emergency Department attendees. Age Ageing. 47:61-68

33. Whooley MA, Avins AL, Miranda J, Browner WS (1997) Casefinding instruments for depression. Two questions are as good as many. J Gen Intern Med. 12:439-445

34. Yesavage JA, Sheikh JI (1986) 9/Geriatric Depression Scale (GDS). Clin Gerontol 5:165-173

35. Scheier MF, Carver CS, Bridges MW (1994) Distinguishing optimism from neuroticism (and trait anxiety, self-mastery, and selfesteem): a reevaluation of the Life Orientation Test. J Pers Soc Psychol 67:1063-1078

36. Rockwood K, Song X, MacKnight C, Bergman H, Hogan DB, McDowell I et al (2005) A global clinical measure of fitness and frailty in elderly people. CMAJ 173:489-495

37. Charlson ME, Pompei P, Ales KL, MacKenzie CR (1987) A new method of classifying prognostic comorbidity in longitudinal studies: development and validation. J Chronic Dis 40:373-383

38. Anderson RT, Cleek H, Pajouhi AS, Bellolio MF, Mayukha A, Hart A et al (2019) Prediction of Risk of Death for Patients Starting Dialysis: A Systematic Review and Meta-Analysis. Clin J Am Soc Nephrol 14:1213-1227

39. Cohen LM, Ruthazer R, Moss AH, Germain MJ (2010) Predicting six-month mortality for patients who are on maintenance hemodialysis. Clin J Am Soc Nephrol 5:72-79

40. Moss AH, Ganjoo J, Sharma S, Gansor J, Senft S, Weaner B et al (2008) Utility of the "surprise" question to identify dialysis patients with high mortality. Clin J Am Soc Nephrol 3:1379-1384

41. Ware J Jr, Kosinski M, Keller SD (1996) A 12-Item Short-Form Health Survey: construction of scales and preliminary tests of reliability and validity. Med Care 34:220-233

42. Weisbord SD, Fried LF, Arnold RM, Rotondi AJ, Fine MJ, Levenson DJ et al (2004) Development of a symptom assessment instrument for chronic hemodialysis patients: the Dialysis Symptom Index. J Pain Symptom Manage 27:226-240

43. van der Willik EM, Meuleman Y, Prantl K, van Rijn G, Bos WJW, van Ittersum FJ et al (2019) Patient-reported outcome measures: selection of a valid questionnaire for routine symptom assessment in patients with advanced chronic kidney disease - a four-phase mixed methods study. BMC Nephrol 20:344

44. Davison SN, Levin A, Moss AH, Jha V, Brown EA, Brennan F, et al. Executive summary of the KDIGO Controversies Conference on Supportive Care in Chronic Kidney Disease: developing a roadmap to improving quality care. Kidney Int. 2015;88:447-459

45. Ottery FD (1996) Definition of standardized nutritional assessment and interventional pathways in oncology. Nutrition 12:S15-19
46. Kosters CM, van den Berg MGA, van Hamersvelt HW (2019) Sensitive and practical screening instrument for malnutrition in patients with chronic kidney disease. Nutrition 72:110643

47. de Boer AH, Oudijk D, Timmermans JM (2012) Self perceived burden from informal care: construction of the EDIZ-plus. Tijdschr Gerontol Geriatr 43:77-88

48. Hamaker ME, Te Molder M, Thielen N, van Munster BC, Schiphorst AH, van Huis LH (2018) The effect of a geriatric evaluation on treatment decisions and outcome for older cancer patients - a systematic review. J Geriatr Oncol 9:430-440

49. Festen S, Kok M, Hopstaken JS, van der Wal-Huisman H, van der Leest A, Reyners AKL et al (2019) How to incorporate geriatric assessment in clinical decision-making for older patients with cancer. An implementation study. J Geriatr Oncol 10:951-959

50. Parker SG, McLeod A, McCue P, Phelps K, Bardsley M, Roberts $\mathrm{HC}$ et al (2017) New horizons in comprehensive geriatric assessment. Age Ageing 46:713-721

51. Gladman JRF, Conroy SP, Ranhoff AH, Gordon AL (2016) New horizons in the implementation and research of comprehensive geriatric assessment: knowing, doing and the 'know-do' gap. Age Ageing 45:194-200

52. van Holstein Y, van Deudekom FJ, Trompet S, Postmus I, den Boogaard A, van der Elst MJT et al (2021) Design and rationale of a routine clinical care pathway and prospective cohort study in older patients needing intensive treatment. BMC Geriatr. 21:29

53. Wildiers H, Heeren P, Puts M, Topinkova E, Janssen-Heijnen ML, Extermann M et al (2014) International Society of Geriatric Oncology consensus on geriatric assessment in older patients with cancer. J Clin Oncol 32:2595-2603

54. Mohile SG, Velarde C, Hurria A, Magnuson A, Lowenstein L, Pandya $C$ et al (2015) Geriatric assessment-guided care processes for older adults: a delphi consensus of geriatric oncology experts. J Natl Compr Canc Netw 13:1120-1130

55. O'Donovan A, Mohile SG, Leech M (2015) Expert consensus panel guidelines on geriatric assessment in oncology. Eur J Cancer Care (Engl) 24:574-589

56. Pilotto A, Sancarlo D, Aucella F, Fontana A, Addante F, Copetti $\mathrm{M}$ et al (2012) Addition of the multidimensional prognostic index to the estimated glomerular filtration rate improves prediction of long-term all-cause mortality in older patients with chronic kidney disease. Rejuvenation Res 15:82-88

57. Nixon AC, Brown J, Brotherton A, Harrison M, Todd J, Brannigan D et al (2020) Implementation of a frailty screening programme and Geriatric Assessment Service in a nephrology centre: a quality improvement project. J Nephrol. https://doi.org/10.1007/ s40620-020-00878-y

58. Aucella F, Corsonello A, Leosco D, Brunori G, Gesualdo L, Antonelli-Incalzi R (2019) Beyond chronic kidney disease: the diagnosis of Renal Disease in the Elderly as an unmet need. A position paper endorsed by Italian Society of Nephrology (SIN) and Italian Society of Geriatrics and Gerontology (SIGG). J Nephrol. 32:165-176

59. Aucella F, Brunori G, Dalmartello M, Leosco D, Paolisso G, Marangella $\mathrm{M}$ et al (2016) Assessment of the geriatric competence and perceived needs of Italian nephrologists: an internet survey. $\mathbf{J}$ Nephrol 29:385-390

60. NL7104 Pathway for OLDer patients with End-stage Renal disease (POLDER). 2018. https://www.trialregister.nl/trial/7104. Accessed August 242020

61. van Oevelen M, Abrahams AC, Bos WJW, Emmelot-Vonk MH, Mooijaart SP, van Diepen M et al (2021) DIALysis or not: Outcomes in older kidney patients with GerIatriC Assessment (DIALOGICA): rationale and design. BMC Nephrol 22:39

62. Dodds RM, Syddall HE, Cooper R, Benzeval M, Deary IJ, Dennison EM et al (2014) Grip strength across the life course: normative data from twelve British studies. PLoS ONE 9:e113637 
63. van der Elst W, van Boxtel MP, van Breukelen GJ, Jolles J (2006) The Letter Digit Substitution Test: normative data for 1,858 healthy participants aged 24-81 from the Maastricht Aging Study (MAAS): influence of age, education, and sex. J Clin Exp Neuropsychol 28:998-1009

64. Dennis M, Kadri A, Coffey J (2012) Depression in older people in the general hospital: a systematic review of screening instruments. Age Ageing 41:148-154

65. Hinz A, Sander C, Glaesmer H, Brähler E, Zenger M, Hilbert A et al (2017) Optimism and pessimism in the general population: psychometric properties of the Life Orientation Test (LOT-R). Int J Clin Health Psychol 17:161-170

Publisher's Note Springer Nature remains neutral with regard to jurisdictional claims in published maps and institutional affiliations. 